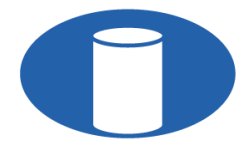

IBRACON Structures and Materials Journal

Revista IBRACON de Estruturas e Materiais

ORIGINAL ARTICLE

\title{
Effect of water/cement ratio on micro-nanomechanical properties of the interface between cementitious matrix and steel microfibers in ultra-high performance cementitious composites
}

\author{
Efeito da relação água/cimento nas propriedades micro-nanomecânicas da \\ interface entre matriz cimentícia e microfibras metálicas em materiais cimentícios \\ de ultra-alto desempenho
}

Vanessa Fernandes Cesari ${ }^{\mathrm{a}}$ (D)

Fernando Pelisser ${ }^{\mathrm{a}}$ (D)

Philippe Jean Paul Gleize ${ }^{\mathrm{a}}$ (1)

Milton Domingos Michel $^{\mathrm{b}}$

${ }^{a}$ Universidade Federal de Santa Catarina - UFSC, Departamento de Engenheira Civil, Florianópolis, SC, Brasil

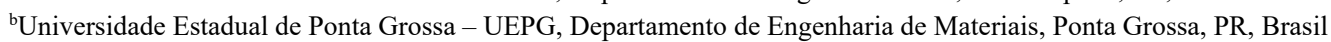

Received 19 July 2020

Accepted 15 November 2020

\begin{abstract}
Ultra-high performance concretes with steel microfibers have been studied in depth with the aim of producing more efficient and durable structures. The performance of these materials depends on the characteristics of the interface between microfibers and cementitious matrix. This research investigates the micro-nanomechanical properties of the interfacial transition zone between the steel microfibers and the matrix of ultra-high performance cementitious composite. The effect of the water/cement ratio and distance from the microfiber were analyzed. The results confirm the formation of high-density calcium-silicate-hydrate (HD C-S-H) matrix at higher concentrations than low-density calcium-silicate-hydrate (LD C-S-H) for w/c ratios of 0.2 and 0.3 . The properties in cementitious matrix interface with steel microfibers were very similar to that measured for the cement paste, and no significant difference was observed regarding the distance to the microfibers in relation to the elastic modulus, hardness and chemical composition. Thus, the authors can conclude that the formation of a less resistant region does not occur at the interfacial transition zone cement paste/microfibers.
\end{abstract}

Keywords: calcium-silicate-hydrate, ultra-high performance concrete, interfacial transition zone, steel microfibers, nanoindentation.

\begin{abstract}
Resumo: Concretos de ultra-alto desempenho com microfibras metálicas têm sido bastante estudados com objetivo de produzir estruturas mais eficientes e duráveis. O desempenho deste material é dependente das características da interface entre as microfibras e a matriz cimentícia. Este trabalho tem como objetivo investigar as propriedades micro-nanomecânicas da zona de transição interfacial entre as microfibras metálicas e a matriz cimentícia de materiais cimentícios de ultra-alto desempenho através das variáveis relação água/cimento e distância da fibra. Os resultados obtidos mostram a formação silicatos de cálcio hidratados de alta densidade (HD C-S-H) em maior quantidade do que silicatos de cálcio hidratados de baixa densidade (LD $\mathrm{C}-\mathrm{S}-\mathrm{H})$ para relações água/cimento de 0,2 e 0,3 . As propriedades medidas na interface entre as microfibras metálicas e a matriz cimentícia foram muito semelhantes àquelas medidas na pasta de cimento. Também não foram observadas diferenças significativas no módulo de elasticidade, dureza e composição química conforme a distância da fibra foi variada. Sendo assim, os autores concluem que não há ocorrência de uma região mais fraca na zona de transição entre a pasta e as microfibras.
\end{abstract}

Palavras-chave: silicato de cálcio hidratado, concreto de ultra-alto desempenho, zona de transição interfacial, microfibras metálicas, nanoindentação.

Corresponding author: Vanessa Fernandes Cesari. E-mail: vanessacesari@yahoo.com.br

Financial support: This work was financed by Coordination for the Improvement of Higher Education Personnel (CAPES), the Foundation for Research and Innovation of the State of Santa Catarina (FAPESC), the National Council of Technological and Scientific Development (CNPq, fellowship under grant number 304589/2019-5). Conflict of interest: Nothing to declare. 
How to cite: V. F. Cesari, F. Pelisser, P. J. P. Gleize, and M. D. Michel, "Effect of water/cement ratio on micro-nanomechanical properties of the interface between cementitious matrix and steel microfibers in ultra-high performance cementitious composites" IBRACON Struct. Mater. J Rev. IBRACON Estrut. Mater., vol. 14, no. 4, e14413, 2021, https://doi.org/10.1590/S1983-41952021000400013

\section{INTRODUCTION}

Ultra-high performance concrete (UHPC) is frequently studied in order to develop more efficient materials for use in engineering projects. UHPC is produced with high binder consumption, a very low water/binder ratio, the absence of large aggregates and the use of steel microfibers [1]. This concrete presents high resistance to both compressive and flexural strength [2]. It is composed of Portland cement, additional cementitious materials and steel microfibers, superplasticizer admixture and proposes the elimination of steel reinforcement in the production of prefabricated slabs of reduced thicknesses. Steel microfibers contribute to reinforcing the concrete due to their size, surface area and the adherence to the cementitious matrix, increasing resistance to microcracking and tensile strength. However, the presence of steel fibers in the matrix, as well as aggregates, act as a solid element, causing the wall effect [3] [4]. According to Scrivener et al. [3], the presence of a solid element prevents the packaging of the particles next to it to be equal to the packaging and distribution of the same particles in the rest of the matrix. This leads to the occurrence of a more fragile zone (interfacial transition zone, ITZ) with different properties from the rest of the matrix.

UHPC are treated as homogeneous continuum materials in macroscale. At mesoscale, cement matrix, aggregates and fiber phases become discernible. Scaling down to nanoscale, material is divided into several phases, e.g. C-S-H, $\mathrm{CH}$ and porosity [4]. Macromechanical properties like strength and ductility of UHPC depends fundamentally on the micro-nanoproperties, especially at the fiber-matrix ITZ [5]. And the bonding between fiber and matrix depends fundamentally on the crystalline nanostructure in ITZ [4]. Increasing the portion of UHD/HD C-S-H and consequently lowing LD C-S-H and porous phase helps densification cementitious matrix and so enhancing fiber-matrix bond. Therefore, studying the properties of the ITZ in micro-nanoscale is fundamental for the development of ultra-high performance cementitious composites.

Water/cement $(\mathrm{w} / \mathrm{c})$ ratios and aggregate size are known to affect the ITZ microstructure and porosity [6]. However, recent studies show that the ITZ in high performance concretes has a packing density of hydration products equivalent to the cementitious matrix. This effect is attributed to the use of silica fume and the very low w/c ratio used [7]. Sorelli et al. [8] were the first to characterize the nanomechanical properties at the interface of the cementitious matrix with steel microfibers, using instrumented nanoindentation. The authors verified that no region showed mechanical properties inferior to the matrix; however only one concrete composition was evaluated at different scale levels from the hydrated cement nanostructure to the aggregates and microfibers used [8].

In contrast, studies have evaluated the effect of nanoparticles of calcium carbonate and nanosilica at the interface between steel microfibers and cementitious matrix in order to improve the characteristics of this region and consequently the mechanical properties of ultra-high performance concretes [5], [9]. Using nanoindentation, Xu et al. [4] conducted comprehensive research to evaluate the effect of two types of microfiber (steel and polypropylene) and w/c ratios of $0.35,0.40$ and 0.45 on the fiber-matrix ITZ. The authors verified that the fiber type lead to ITZs with different thicknesses, $30 \mu \mathrm{m}$ for steel and $15 \mu \mathrm{m}$ for polypropylene fibers. The effect of the $\mathrm{w} / \mathrm{c}$ ratio was also significant mainly regarding the packing of the C-S-H particles [4]. More high-density C-S-H regions (HD C-S-H, with elastic modulus $\mathrm{E} \approx 30 \mathrm{GPa}$ ) and less low-density C-S-H regions (LD C-S-H, with elastic modulus $\mathrm{E} \approx 20 \mathrm{GPa}$ ) were observed, in different proportions, when the w/c ratio was reduced [4]. However, the research did not include a w/c ratio close to 0.2 , which is characteristic of UHPC.

Given the above, in this research, the micro-nanomechanical properties of the ITZ between steel microfibers and the cementitious matrix were evaluated for low w/c ratios $(0.20$ and 0.30$)$ mixtures aiming to study C-S-H particle packing in order to contribute to the development of UHPC. Instrumented nanoindentation and scanning electron microscopy combined with chemical analysis by energy-dispersive spectrometry (SEM-EDS) techniques were used as tools to evaluate the mechanical properties of the material.

\section{MATERIALS AND EXPERIMENTAL PROGRAM}

\subsection{Materials}

Concrete pastes were produced using the following materials: i) Portland cement CPII-F-40 (similar to CEM II-EN 197-1), with 6 to $10 \%$ limestone addition and compressive strength of $40 \mathrm{MPa}$ at the age of 28 days according to 
Brazilian standard NBR 16697 [10]; ii) polycarboxylate-based superplasticizer ADVA ${ }^{\mathrm{TM}}$ CAST 585 (Grace Construction Products); and iii) steel microfibers, commercially known as Dramix ${ }^{\circledR}$ OL 13/.20 (Bekaert), $0.20 \mathrm{~mm}$ in diameter and $13 \mathrm{~mm}$ in length, with a form factor $(1 / \mathrm{d})$ of 65 .

Water/cement ratio and fiber content ranged from 0.2 to 0.3 and from 0 to $2 \%$ by weight of cement, respectively. Fiber content of $2 \%$ corresponds to approximately $0.4 \%$ of total paste volume (vf $=0.4)$. Superplasticizer content was kept constant at $1 \%$ by weight of cement.

\subsection{Mixing procedure}

A planetary type, vertical axis, speed adjustable mixer with two speed grades and 5 liters capacity was used for the following mixing steps: a) add superplasticizer to water content and mix; b) mix at low speed while adding the cement over $30 \mathrm{~s}$; c) mix at low speed for a further $30 \mathrm{~s}$, total $1 \mathrm{~min}$; d) mix at high speed for $1 \mathrm{~min}$; e) return to low speed and mix for $30 \mathrm{~s}$ while adding the steel fibers; f) mix at low speed for a further $30 \mathrm{~s}$, total $3 \mathrm{~min}$; g) stop mixing and scrape the material adhered to the walls of the bowl using a spatula; h) restart mixing at high speed for $2 \mathrm{~min}$, total $5 \mathrm{~min}$.

Cylindrical samples measuring $20 \times 35 \mathrm{~mm}$ (diameter $\times$ height) were casted. The specimens were demolded 24 hours after casting and were then placed in water immersion cure (temperature $23 \pm 2^{\circ} \mathrm{C}$ ) until the test date (28 days).

\subsection{Sample preparation}

Samples were cut approximately $5 \mathrm{~mm}$ thick using a low speed metallographic cutter (Buehler Isomet) and diamond blades.

During the first step, the sample surface was polished using silicon carbide papers (800, 1200 and 2000 grades), approximately $10 \mathrm{~min}$ each, while constantly monitoring preparation efficiency under an optical microscope. During the second step, polishing was performed using diamond spray particles (four stages of increasing fineness, $6 \mu \mathrm{m}, 3$ $\mu \mathrm{m}, 1 \mu \mathrm{m}$ and $0.25 \mu \mathrm{m}$ ) to obtain a very flat, smooth surface finish [11]. The samples were polished for approximately $30 \mathrm{~min}$ at each stage, using a $450 \mathrm{rpm}$ rotation. After each grinding/polishing stage, the samples were placed in an ultrasonic bath $(15 \mathrm{~min})$ to remove dust and diamond particles left on the surface or in the porous structure. After preparation, the samples were stored in a vacuum desiccator until tested.

\subsection{Nanoindentation investigation}

Elastic modulus and hardness were determined using a Berkovich indenter following the method described by Oliver and Pharr [12].

Hardness is obtained by penetrating the indenter the surface of the sample until a given load. Shortly after removing the load, the sample is analyzed under an optical microscope to determine the area of the residual plastic impression. Hardness is defined as the ratio between the maximum penetration load and the area measured.

Elastic modulus is obtained from load-unload curves constructed with the nanoindentation test results and is determined by the slope of the unloading curve according to Equation 1:

$\mathrm{E}_{\mathrm{r}}=\frac{\sqrt{\pi} \cdot \mathrm{S}_{\mathrm{max}}}{2 \cdot \beta \cdot \sqrt{\mathrm{A}}}$

Equation 1

where " $\beta$ " is a constant dependent on the indenter geometry, " $\mathrm{S}_{\max }$ " is the rigidity obtained experimentally from the upper part of the unloading curve, "A" is the projected contact area, "P" is the load and " $h$ " is the displacement of the indenter, such that (Equation 2):

$$
\mathrm{S}_{\max }=\frac{\mathrm{dP}}{\mathrm{dh}}
$$

Equation 2

where " $E_{r}$ " is the reduced elastic modulus, which includes the effects of non-rigid indenters, i.e. it is related to the elastic modulus of the sample and the indenter through Equation 3:

$$
\frac{1}{\mathrm{E}_{\mathrm{r}}}=\frac{1-v_{\mathrm{i}}^{2}}{\mathrm{E}_{\mathrm{i}}}+\frac{1-v^{2}}{\mathrm{E}}
$$


where " $E_{i}$ " and " $v_{i}$ " are the elastic modulus and the Poisson ratio of the indenter material and "E" and " $v$ " are the elastic modulus the Poisson ratio of the penetrated material.

Nanomechanical properties were determined in cement pastes with and without microfibers using two loads, 100 $\mathrm{mN}$ and $50 \mathrm{mN}$, corresponding to matrix A and matrix B, respectively. Each matrix was composed of four rows with seven indentation points approximately $30 \mu \mathrm{m}$ from each other, i.e. 28 indentations in each matrix ( $4 \times 7$ points). The technique was also performed in two $(3 \times 8)$ complementary matrices (matrix 1 and matrix 2 ) placed near the interface between the cementitious matrix and steel microfiber, i.e. 24 indentations, and one $(4 \times 7)$ matrix over the fiber surface, i.e. 28 indentations approximately $30 \mu \mathrm{m}$ from each other. SEM micrographs show the regions at the microfiber-paste interface. Chemical analysis by Energy Dispersive x-ray Spectrometry (EDS) was also performed at the interface with the microfiber to investigate chemical changes and determine any association between these changes and microstructural and mechanical changes. Loads of $50 \mathrm{mN}$ and $100 \mathrm{mN}$ were used to investigate a slightly larger contact area.

\section{RESULTS}

\subsection{Cement Paste}

Micro-nanoscale instrumented nanoindentation was used to measure the hardness and elastic modulus of the pastes and the microfiber-paste interface. Figure 1 shows the results of hardness and elastic modulus for w/c ratios of 0.2 and 0.3 using loads of $100 \mathrm{mN}$ (matrix A) and $50 \mathrm{mN}$ (matrix B). Figure 2 shows that the most significant effect of microfiber addition was on hardness and the least significant was on the elastic modulus. The load variation between 100 and $50 \mathrm{mN}$ applied in the matrices A and B, respectively (Figure 1 and Figure 2), showed no significant effect. This could be associated with the homogeneity of the material analyzed.

Although the loads used $(50$ and $100 \mathrm{mN}$ ) are higher than that recommended to characterize the nanomechanical properties of cement $(2 \mathrm{mN})$, the objective was to characterize a slightly wider area in relation to the surface, especially at the interface with microfibers. However, to achieve this, previous studies were also considered. In their study on the nanomechanical properties of two types of synthesized cement (Ca/Si ratios of 0.7 and 2.1), Pelisser et al. [13] observed no significant differences in the nanomechanical properties of C-S-H among loads of $2 \mathrm{mN}, 4 \mathrm{mN}, 8 \mathrm{mN}, 16 \mathrm{mN}$ and $32 \mathrm{mN}$ loads. Matrices were also evaluated using $1 \mathrm{mN}, 2 \mathrm{mN}, 4 \mathrm{mN}, 8 \mathrm{mN}, 16 \mathrm{mN}, 32 \mathrm{mN}, 64 \mathrm{mN}, 128 \mathrm{mN}, 256 \mathrm{mN}$ and $512 \mathrm{mN}$, in which minor differences were observed between the smallest and largest loads adopted [13]. Other authors have also verified that there are no significant differences in the micro-nanomechanical properties of cement, measured between 10 and $300 \mathrm{mN} \mathrm{[14]} \mathrm{and} \mathrm{between} 6$ and $50 \mathrm{mN}$ [15].

The w/c ratio had a significant effect on the results of the nanomechanical tests, achieving values of $34 \mathrm{GPa}$ and 28 GPa for elastic modulus and $0.87 \mathrm{GPa}$ and $0.80 \mathrm{GPa}$ for hardness, when using w/c ratios of 0.2 and 0.3 , respectively (matrix A). The difference was approximately $20 \%$ for elastic modulus and $10 \%$ for hardness, and this is the result of an increase in packing density of C-S-H particles for a w/c ratio of 0.2 . The histograms in Figure 3 show major formation of C-S-H particles with higher hardness (Figure 3a) and elastic modulus (Figure $3 \mathrm{~b}$ ) for a w/c ratio of 0.2 compared with that of 0.3 . Considering that LD C-S-H particles have a characteristic elastic modulus below $25 \mathrm{GPa}$ and HD CS-H above $25 \mathrm{GPa}$, the results show the formation of $96 \%$ of HD C-S-H and $4 \%$ of LD C-S-H when the w/c ratio was 0.2 , and $63 \%$ of HD C-S-H and $37 \%$ of LD C-S-H when the w/c ratio was 0.3 .

Several authors [16], [17] have stated that C-S-H can be divided into two types, low-density (LD C-S-H) and highdensity (HD C-S-H), which show elastic modulus results of around $18 \mathrm{GPa}$ (LD C-S-H or E<25GPa) and $29 \mathrm{GPa}$ (HD $\mathrm{C}-\mathrm{S}-\mathrm{H}$ or $E>25 \mathrm{GPa}$ ), and approximate hardness of $0.4 \mathrm{GPa}$ (LD C-S-H) and $0.8 \mathrm{GPa}$ (HD C-S-H). A phase denominated ultra-high density (UHD) C-S-H is formed when very low w/c ratios are used, and it exceeds the values of nanomechanical properties of HD C-S-H, with approximate $E$ and $H$ values of 40-50 GPa and 1.5-2 GPa, respectively, slightly below the results obtained for calcium hydroxide [16]. Considering that, results show the formation of $96 \%$ of HD C-S-H and $4 \%$ of LD C-S-H when the w/c ratio was 0.2 , and $63 \%$ of HD C-S-H and $37 \%$ of LD C-S-H when the w/c ratio was 0.3 .

When evaluating the effect of the $\mathrm{w} / \mathrm{c}$ ratios $(0.2$ and 0.3$)$ by instrumented nanoindentation, Vandamme, et al. [17] observed the predominant formation of HD C-S-H and UHD C-S-H for a w/c of $0.20(97 \%$ HD C-S-H and UHD C-S$\mathrm{H}$ and 3\% LD C-S-H) and a significant reduction in HD C-S-H and UHD C-S-H for a w/c of 0.30 (70\% HD C-S-H and UHD C-S-H and 30\% LD C-S-H). These results were obtained for a cementitious matrix without microfibers. 


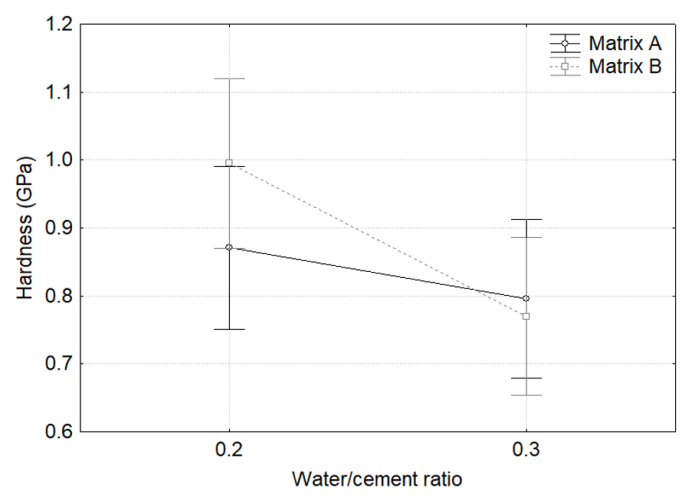

a)

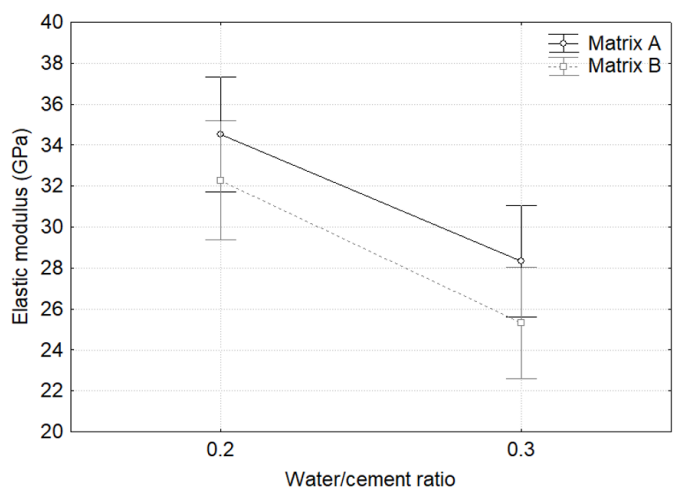

b)

Figure 1. Results of hardness (a) and elastic modulus (b) obtained by the nanoindentation technique applied to cement pastes with $\mathrm{w} / \mathrm{c}$ ratios of 0.2 and 0.3 without steel microfibers, varying the load from $100 \mathrm{mN}$ (matrix A) to $50 \mathrm{mN}$ (matrix B).

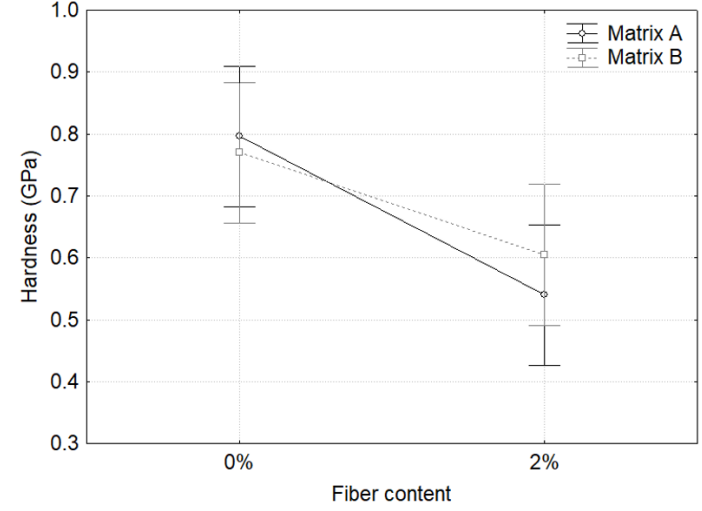

a)

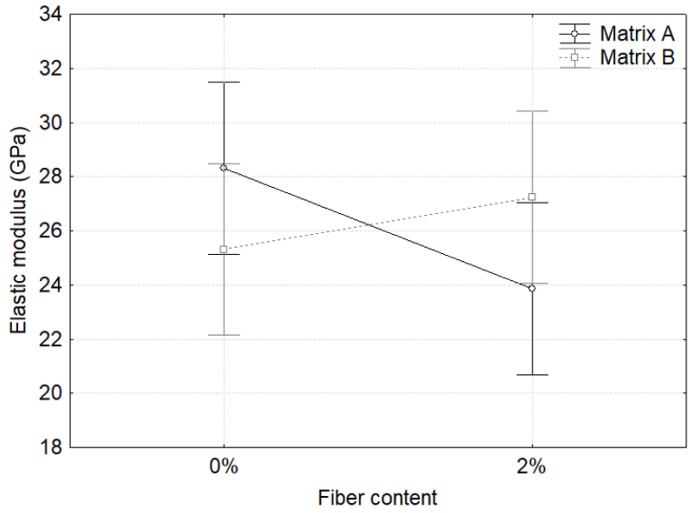

b)

Figure 2. Results of hardness (a) and elastic modulus (b) obtained by the nanoindentation technique applied to cement pastes with $\mathrm{w} / \mathrm{c}$ ratio of 0.3 with and without steel microfibers, varying the load from $100 \mathrm{mN}$ (matrix A) to $50 \mathrm{mN}$ (matrix B).

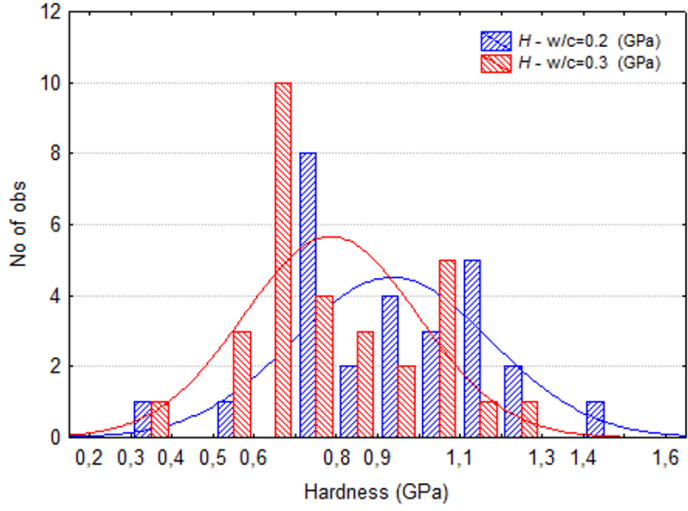

a)

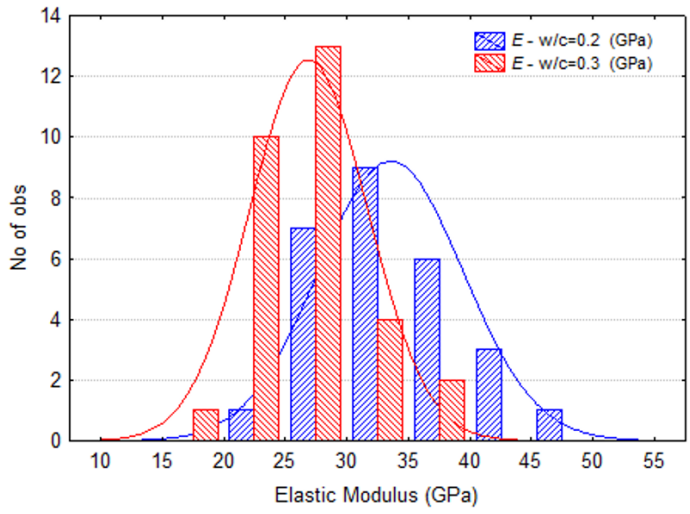

b)

Figure 3. Histogram showing the effect of the w/c ratio on the hardness (a) and elastic modulus (b). 


\subsection{Interfacial transition zone cement paste/microfiber}

Considering the micro-nanomechanical characterization performed here, at the matrix-steel microfiber interface, Figure 4 and Figure 5 show micrographs of the two matrices (matrix 1 and 2, with w/c=0.30) near the paste-fiber interface on each side of the same microfiber. Matrix 1 was placed slightly further away from the microfiber, a distance of $\sim 60 \mu \mathrm{m}$, due to the microporosity observed at the interface with the fiber (Figure 4), while matrix 2 was placed closer, a distance of $\sim 30 \mu \mathrm{m}$.

Figure 6 presents the hardness and elastic modulus results, considering the effect of the distance of each row of indentation points in relation to the microfiber. For matrix 1 (farther from the microfiber), a tendency towards increased hardness and a greater increase in the elastic modulus was observed when the distance from the microfiber was greater. This resulted in a mean elastic modulus of approximately $30 \mathrm{MPa}, 40 \mathrm{MPa}$ and $45 \mathrm{MPa}$ (Figure 6b) for distances of approximately $60 \mu \mathrm{m}$ (row 3), $90 \mu \mathrm{m}$ (row 2) and $120 \mu \mathrm{m}$ (row 1), respectively. Although matrix 1 shows some variation regarding microfiber distance, this variation was not significant $(\mathrm{p}=0.087)$, as observed in the statistical analysis (ANOVA) (Table 1). A significant difference was observed between the two matrices $(\mathrm{p}=0.044)$, performed on both sides of the fiber, such that the approximate mean value of the elastic modulus for matrix 1 was $38 \pm 4 \mathrm{GPa}$ and for matrix 2 was $32 \pm 4 \mathrm{GPa}$.

Table 1. ANOVA for elastic modulus (GPa).

\begin{tabular}{cccccc}
\hline Factor $(\mathbf{G P a})$ & SS & dF & MS & F-value & p-value \\
\hline Matrix & 469.68 & 1 & 469.68 & 4.3793 & 0.044939 \\
\hline Row & 567.71 & 2 & 283.86 & 2.6467 & 0.087382 \\
\hline Matrix $\times$ Row & 167.09 & 2 & 83.54 & 0.7790 & 0.467941 \\
\hline Error & 3217.49 & 30 & 107.25 & & \\
\hline
\end{tabular}

SS: sum of squares; dF: degrees of freedom; MS: mean squares.

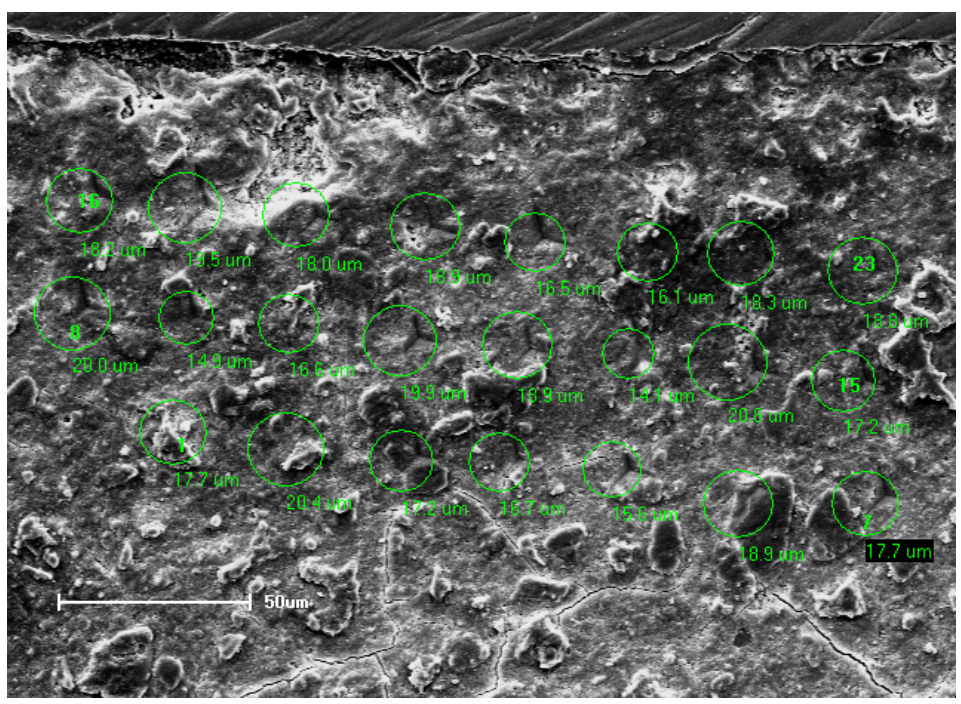

Figure 4. Micrograph (400X) of indentation matrix 1 located at the steel microfiber-paste interface showing all 24 indentation points $\sim 30 \mu \mathrm{m}$ from each other, distributed in 8 columns and 3 rows ( 24 points highlighted).

Regarding the formation of the LD C-S-H and HD C-S-H phases, matrix 1 showed 14\% LD C-S-H and 84\% HD C-S-H, while matrix 2 showed 27\% LD C-S-H and 73\% HD C-S-H. Considering all the results at the interface with the microfiber, since no significant difference was observed between the indentation distances, the formation of $20 \% \mathrm{LD}$ C-S-H and $80 \%$ HD C-S-H was verified. These results are very similar to those obtained for the cementitious matrix without fibers, particularly those obtained for matrix 2; moreover, they reinforce the fact that the micro-nanomechanical properties at the interface with the steel microfibers are equivalent to the cementitious matrix. Results also showed a significant increase in HD C-S-H (80\%) compared with those obtained by Xu et al. [4] for a w/c ratio of 0.35 (31\% HD 
C-S-H). Authors verified the formation of low modulus C-S-H ( $\sim 13 \mathrm{GPa})$, characterized by a region of porosity, probably due to the higher $\mathrm{w} / \mathrm{c}$ ratio. The results obtained in the present work were also very similar to those reported by Vandamme et al. [17], who obtained 70\% HD C-S-H and 30\% LD C-S-H formation for a w/c ratio of 0.3, while determining the nanomechanical properties of cementitious pastes with low $\mathrm{w} / \mathrm{c}$ ratios (between 0.15 and 0.40 ).

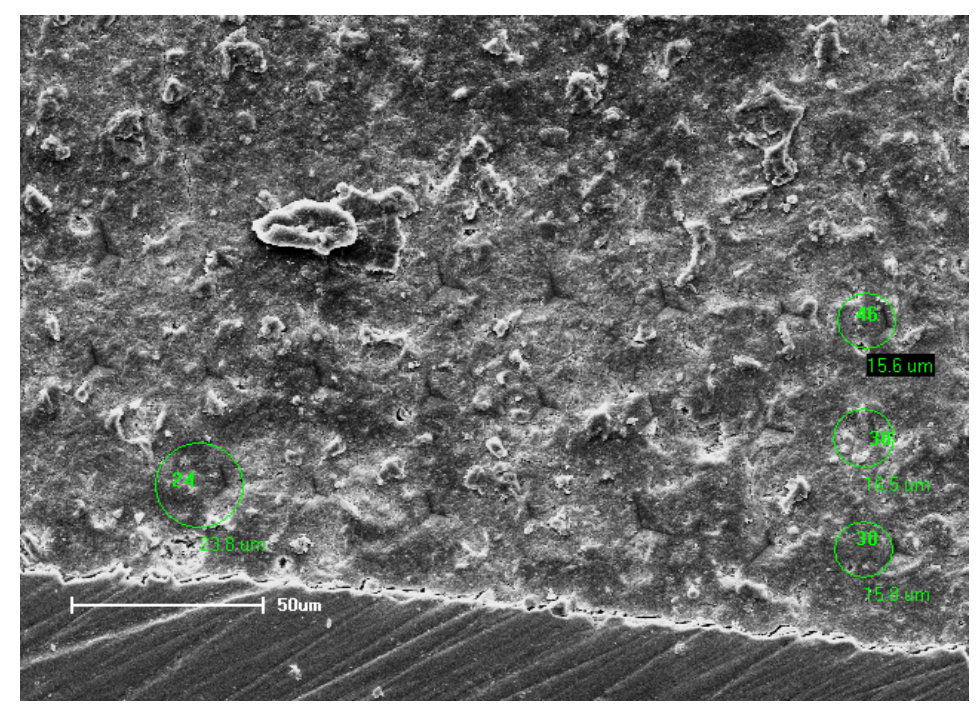

Figure 5. Micrograph (400X) of indentation matrix 2 located at the steel microfiber-paste interface showing all 24 indentation points $\sim 30 \mu \mathrm{m}$ from each other, distributed in 8 columns and 3 rows ( 4 points highlighted).

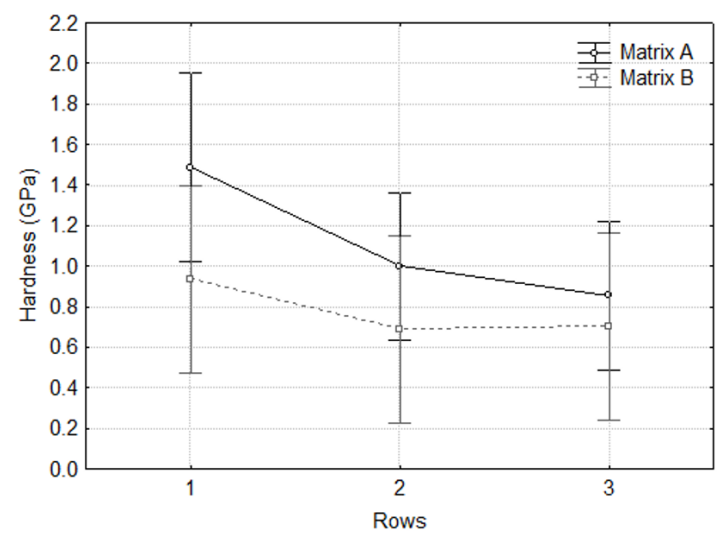

a)

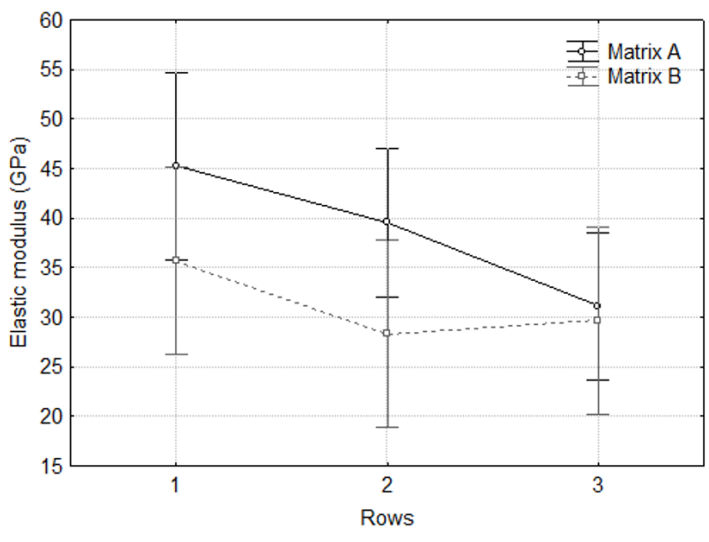

b)

Figure 6. Mean results of hardness (a) and elastic modulus (b) obtained by the nanoindentation technique for two different 24 indentation points matrices located at the microfiber-paste interface, where row 1 is the farthest and row 3 is the closest to the fiber.

Figure 7 shows the load versus displacement curves, indicating the mean values for each row of matrix 2 . Figure 8 presents an indentation curve, characterized as a non-hydrated cement particle, due to the high elastic modulus [17]; this was the only value excluded from the mean results (Figure 6). Figure 9 shows the relation between the results of elastic modulus and hardness, together with histograms, for the two matrices. The elastic modulus results were predominantly between $20 \mathrm{GPa}$ and $40 \mathrm{GPa}$ and $\mathrm{HD} \mathrm{C}-\mathrm{S}-\mathrm{H}(\mathrm{E}>25 \mathrm{GPa})$ formation was much higher than that of LD C-S-H. 


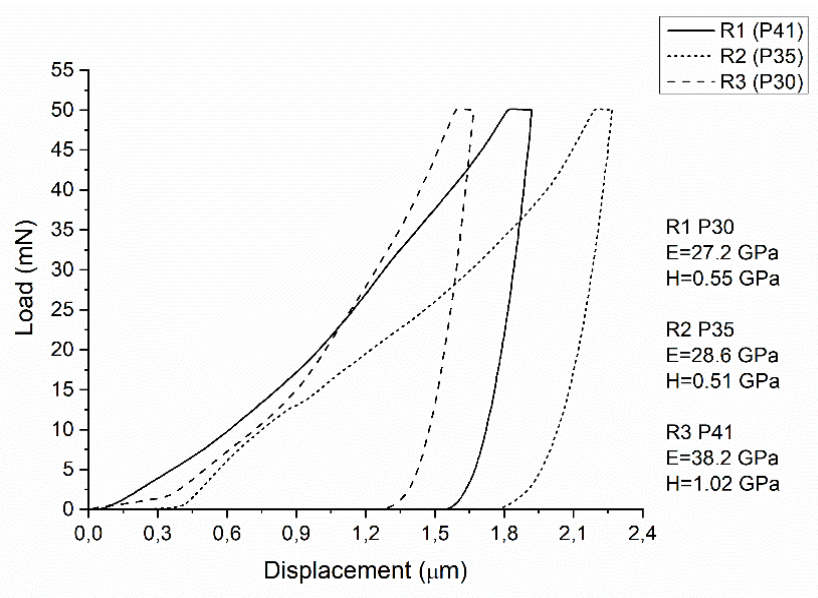

Figure 7. Matrix 2: force versus displacement curves showing representative indentation for each row (R1, R2, R3).

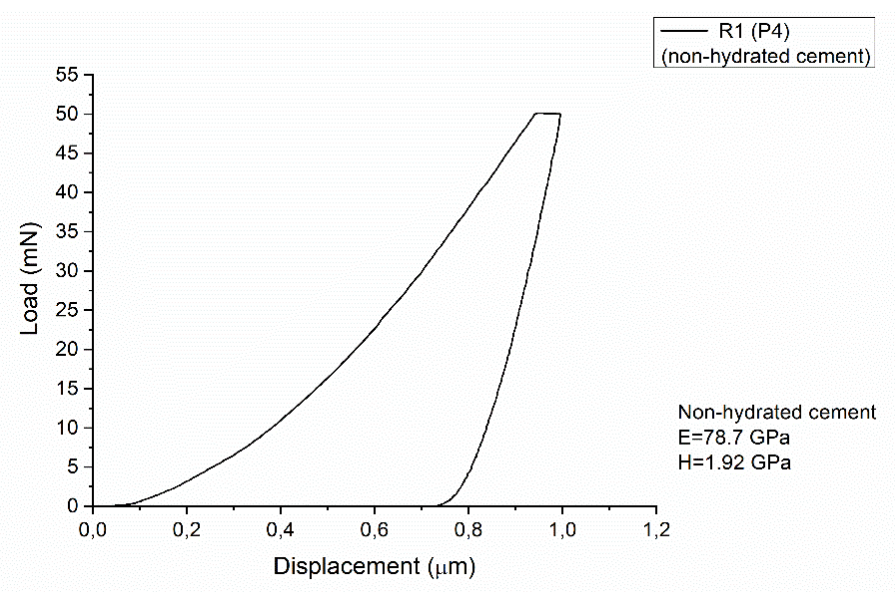

Figure 8. Force versus displacement curve showing particle indentation of non-hydrated cement.
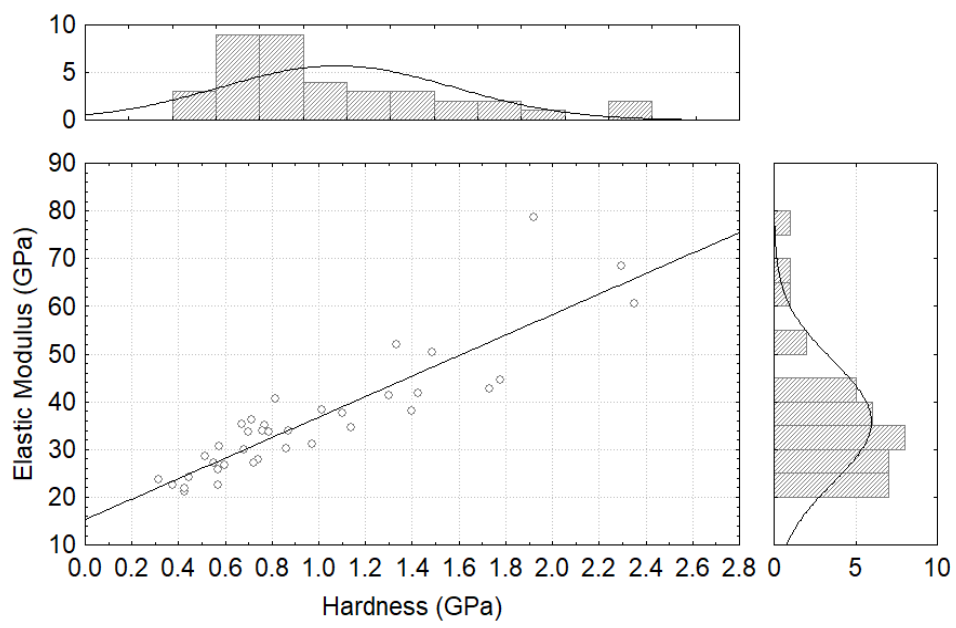

Figure 9. Relation between results of elastic modulus and hardness obtained by the nanoindentation technique for matrices 1 and 2 and histograms. 
Table 2 shows that similar behavior was observed at the steel microfiber-cementitious matrix interface, where the mean values of elastic modulus varied between $28 \mathrm{GPa}$ and $45 \mathrm{GPa}$ and those of hardness varied between $0.7 \mathrm{GPa}$ and $1.5 \mathrm{GPa}$. Regarding the distance between the microfiber and the micro-nanomechanical properties of the cementitious matrix, no significant differences were verified in the results.

Table 2. Average results obtained at the steel microfiber-cementitious matrix interface.

\begin{tabular}{cccccc}
\hline \multicolumn{1}{c}{ Matrix 1 } & \multicolumn{2}{c}{ Matrix 2 } \\
\hline Row & Hardness (GPa) & Elastic Modulus (GPa) & Row & Hardness (GPa) & Elastic Modulus (GPa) \\
\hline \multirow{2}{*}{$1-120 \mu \mathrm{m}$} & $1.49 \pm 0.61$ & $45.3 \pm 10.4$ & $\begin{array}{c}1- \\
90 \mu \mathrm{m}\end{array}$ & $0.94 \pm 0.50$ & $35.7 \pm 15.0$ \\
\hline \multirow{2}{*}{$2-90 \mu \mathrm{m}$} & $1.00 \pm 0.57$ & $39.6 \pm 12.2$ & $\begin{array}{c}2- \\
60 \mu \mathrm{m}\end{array}$ & $0.69 \pm 0.40$ & $28.3 \pm 6.0$ \\
\hline \multirow{2}{*}{$3-60 \mu \mathrm{m}$} & $0.86 \pm 0.52$ & $31.1 \pm 8.7$ & $\begin{array}{c}3- \\
30 \mu \mathrm{m}\end{array}$ & $0.70 \pm 0.30$ & $29.7 \pm 5.9$ \\
\hline Mean & $1.06 \pm 0.59$ & $37.7 \pm 11.6$ & Mean & $0.78 \pm 0.40$ & $31.2 \pm 9.8$ \\
\hline
\end{tabular}

In addition, an indentation matrix $(4 \times 7)$ was also performed on the microfiber inserted in the paste (Figure 10$)$ and the mean hardness value was $6.66 \pm 0.11 \mathrm{GPa}$, while the mean elastic modulus was $178.2 \pm 2.55 \mathrm{GPa}$. The indentation results presented low variability and were similar to those obtained by Sorelli et al. [8] who reported approximately 202 $\pm 20 \mathrm{GPa}$.

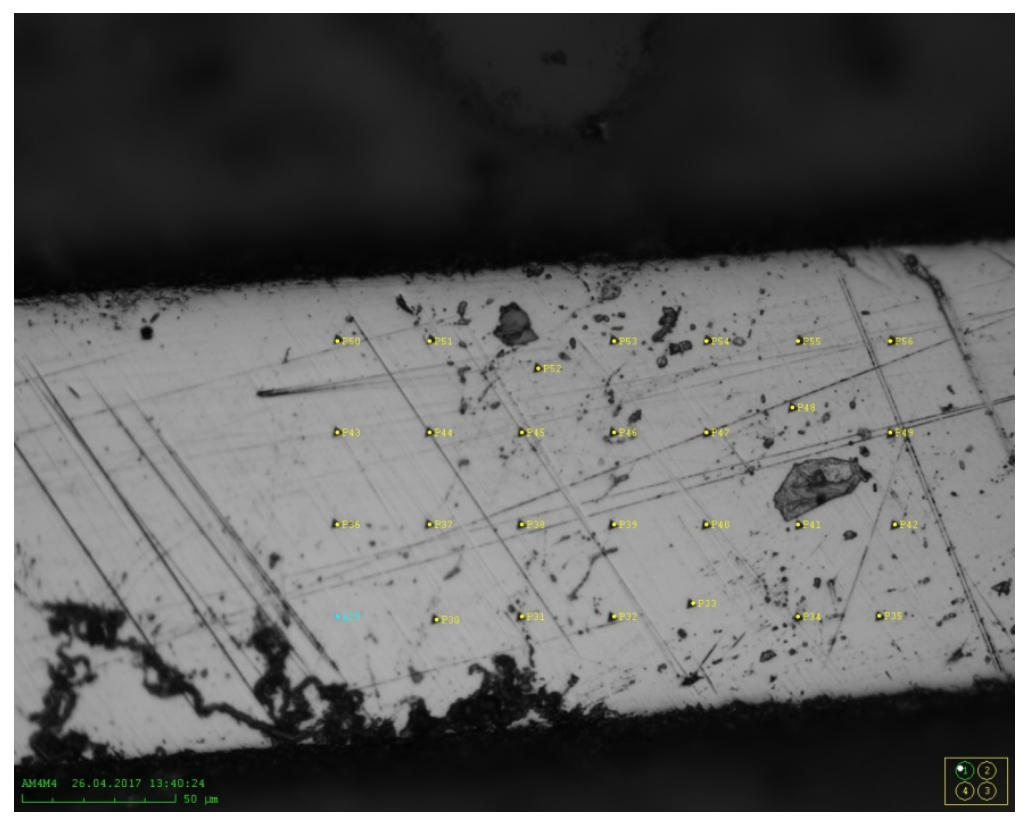

Figure 10. Micrograph (1000X) of an indentation matrix located on the surface of a steel microfiber showing all 28 indentation points $\sim 30 \mu \mathrm{m}$ from each other, distributed in 7 columns and 4 rows.

\subsection{Interfacial transition zone: chemical characterization}

In addition, four chemical analyses (EDS) were performed at the microfiber-paste interface, within an area of approximately $100 \mu \mathrm{m}^{2}$, from the closest point (D1 - Table 3) to the farthest from the fiber (D4 - Table 3). These analyses were performed at two different sites around the fiber to detect any local changes in calcium (Ca) and calcium hydroxide $(\mathrm{CH})$ concentrations. Table 3 presents the EDS results for two sites around the fiber. The authors analyzed other zones at the microfiber-paste interface and showed similar behavior to those presented here (results not shown).

A higher concentration of $\mathrm{Ca}$ (influencing the $\mathrm{Ca} / \mathrm{Si}$ ratio) was verified at D1 compared with D2, D3 and D4 in zone 1. However, analysis in zone 2 did not confirm these results; rather higher Ca concentrations were verified at D1 and 
D4, while D2 and D3 presented lower concentrations. Thus, it can be concluded that calcium concentration varies locally and this appears to be independent of the proximity to the microfiber.

Table 3. Chemical composition at the steel microfiber-cementitious matrix interface.

\begin{tabular}{|c|c|c|c|c|c|c|c|c|}
\hline \multirow{2}{*}{ Element } & \multicolumn{4}{|c|}{ Region 1} & \multicolumn{4}{|c|}{ Region 2} \\
\hline & D1 & D2 & D3 & D4 & D1 & D2 & D3 & D4 \\
\hline $\mathrm{Ca}$ & 39.70 & 30.38 & 29.86 & 31.63 & 37.66 & 36.16 & 34.79 & 37.36 \\
\hline $\mathrm{O}$ & 32.27 & 31.55 & 33.19 & 31.91 & 27.44 & 30.39 & 30.89 & 28.92 \\
\hline $\mathrm{C}$ & 15.30 & 14. 12 & 14.79 & 12.32 & 13.00 & 12.95 & 14.33 & 13.14 \\
\hline $\mathrm{Si}$ & 4.45 & 10.91 & 10.75 & 11.91 & 7.10 & 9.55 & 9.10 & 7.48 \\
\hline K & 2.75 & 5.14 & 5.13 & 5.82 & 4.11 & 4.74 & 4.05 & 3.49 \\
\hline $\mathrm{Fe}$ & 4.40 & 4.33 & 3.05 & 3.02 & 7.94 & 3.44 & 3.15 & 5.33 \\
\hline $\mathrm{Al}$ & 0.00 & 2.45 & 2.07 & 2.51 & 1.77 & 2.04 & 2.13 & 2.69 \\
\hline $\mathrm{Mg}$ & 1.12 & 1.12 & 1.16 & 0.88 & 0.98 & 0.72 & 1.14 & 1.36 \\
\hline \multirow[t]{4}{*}{$\mathrm{Ca} / \mathrm{Si}$} & 8.92 & 2.78 & 2.78 & 2.66 & 5.30 & 3.79 & 3.82 & 4.99 \\
\hline & \multicolumn{4}{|c|}{$202(4)$} & \multicolumn{4}{|c|}{$202(7)$} \\
\hline & \multicolumn{4}{|c|}{2797 _65035 } & \\
\hline & \multicolumn{4}{|c|}{ 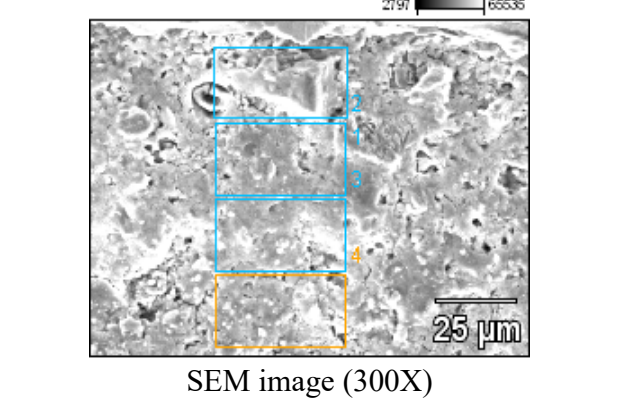 } & \multicolumn{4}{|c|}{ 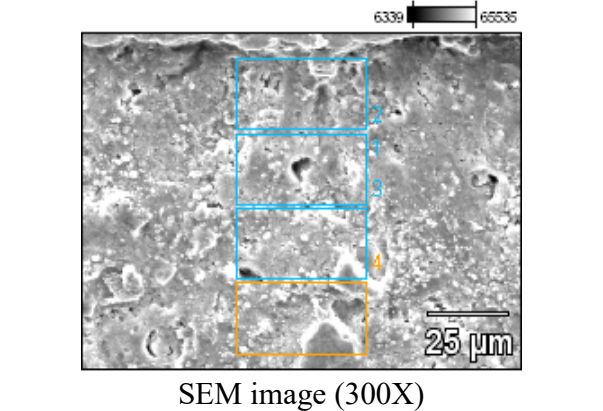 } \\
\hline
\end{tabular}

In addition, Figure 11 shows a micrograph of the surface of the microfiber where chemical analysis (EDS), performed at two spots, showed the presence of $\mathrm{Zn}, \mathrm{Cu}$ and $\mathrm{Fe}$ in approximate quantities of $75 \%, 20 \%$ and $5 \%$, respectively.

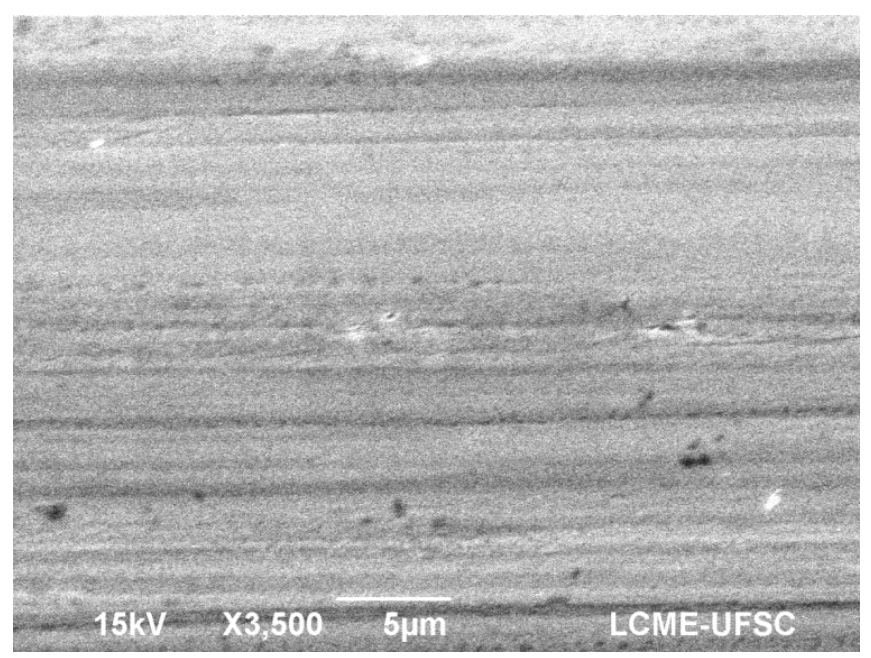

Figure 11. Micrograph (3500X) of the surface of a steel microfiber. 


\section{DISCUSSION}

$\mathrm{Xu}$ et al. [4] studied the ITZ between steel microfibers and cementitious matrix of cement pastes with w/c ratios from 0.35 to 0.45 and showed that the $\mathrm{w} / \mathrm{c}$ ratio had a significant effect on the nanomechanical properties. Results showed the formation of LD C-S-H of $26 \%, 37 \%, 32 \%$ and HD C-S-H of 31\%, 23\%, 15\%, for w/c ratios of $0.35,0.40$ and 0.45 , respectively. Other phases were also identified, such as $\mathrm{CH}(\mathrm{E}>50 \mathrm{GPa})$ and clinker (E>80 GPa). Authors also observed an increase in HD C-S-H from $15 \%$ to $31 \%$ when the w/c ratio decreased from 0.45 to 0.35 .

However, $\mathrm{Xu}$ et al. [4] concluded that the distance was not significant in determining nanomechanical properties in their evaluation of the combined effect of the $\mathrm{w} / \mathrm{c}$ ratio and the distance (from $5 \mu \mathrm{m}$ to $50 \mu \mathrm{m}$ ) between the indentation and the steel microfiber interface (500 $\mu \mathrm{m}$ in diameter and $13 \mathrm{~mm}$ in length). The authors observed a trend towards reduction, explained by the fact that steel fibers show hydrophilic behavior, i.e. water can spread along their surface. After 28 days, a layer of iron oxide forms on the surface, making the surface more hydrophilic and causing an increase in the $\mathrm{w} / \mathrm{c}$ ratio at the interface, because the fiber is not absorbent [18].

Sorelli et al. [8] characterized UHPC (w/c between 0.19 and 0.21) at several levels (level 1: C-S-H matrix; level 2: cement paste; level 3: concrete; level 4: UHPC). Based on a combination of nanoindentation tests, SEM and XRD, the authors concluded there is strong evidence that there is no interface zone between the matrix and fibers in UHPC. This is due to the predominant presence of HD C-S-H in UHPC, which guarantees the uniform composite behavior of the cementitious matrix.

In this study, a reduction in the $\mathrm{w} / \mathrm{c}$ ratio to values below 0.35 , of 0.30 and 0.20 , caused a significant increase in the mechanical properties of the C-S-H, leading to the formation of $63 \%(0.30)$ and $96 \%(0.20)$ of HD C-S-H. The formation of HD C-S-H doubles for a w/c ratio of 0.30 (63\%), in relation to 0.35 [4], and triples for a w/c ratio of 0.20 (96\%), in relation to 0.35 [4]. These results are close to those obtained by Sorelli et al. [8], when quantifying the percentage of HD C-S-H formation in UHPC $(86 \%)$ by nanoindentation, and the results obtained by Vandamme et al. [17], who verified the formation of $97 \%$ of HD C-S-H, for a w/c ratio of 0.20 , when evaluating only pastes without fibers.

The mentioned authors [4], [8] confirmed that the micro-nanomechanical properties of the cementitious matrix are the same at the interface with steel microfibers, considering $\mathrm{w} / \mathrm{c}$ ratios between 0.20 and 0.45 . They also reported a predominant formation of HD C-S-H for a w/c ratio of 0.20 , while for a $\mathrm{w} / \mathrm{c}$ ratio of 0.30 , there was a significant reduction in the formation of $\mathrm{HD} \mathrm{C}-\mathrm{S}-\mathrm{H}$.

\section{CONCLUSIONS}

This research evaluated the effect of the $\mathrm{w} / \mathrm{c}$ ratio and the micro-nanomechanical behavior at the steel microfibercementitious matrix interface on the development of ultra-high performance cementitious composite.

The effect of w/c ratios of 0.2 and 0.3 on the micro-nanomechanical properties of the cementitious matrix were significant, with $34 \mathrm{GPa}$ and $28 \mathrm{GPa}$ for elastic modulus and $0.87 \mathrm{GPa}$ and $0.80 \mathrm{GPa}$ for hardness, respectively. This difference was due to a higher density of packing of C-S-H particles, forming more HD C-S-H. The results show the formation of $96 \%$ HD C-S-H and 4\% LD C-S-H when the w/c ratio was 0.2, and 63\% HD C-S-H and 37\% LD C-S-H when the $\mathrm{w} / \mathrm{c}$ ratio was 0.3 .

The results obtained at the interface with the steel microfibers were practically the same as those obtained for the cementitious matrix. Thus, the authors can conclude that the formation of a less porous or less resistant region does not occur at the interface with the steel microfibers. The predominant formation of HD C-S-H ( $80 \%)$ in relation to LD CS-H (20\%) was verified.

The good adhesion of the cementitious matrix with the steel microfibers explains the satisfactory performance of ultra-high strength concretes, particularly regarding their tensile strength. Improvements in the mechanical performance, economic aspects and durability studies are fundamental to disseminate the knowledge and application of this type of concrete.

\section{ACKNOWLEDGEMENTS}

The authors gratefully acknowledge the financial support of the Coordination for the Improvement of Higher Education Personnel (CAPES), the Foundation for Research and Innovation of the State of Santa Catarina (FAPESC), the National Council of Technological and Scientific Development (CNPq, fellowship under grant number 304589/2019-5), the Central Laboratory of Electronic Microscopy of the Federal University of Santa Catarina (LCMEUFSC) for the SEM micrographs and Belgo Bekaert for donating the fibers used herein. 


\section{REFERENCES}

[1] C. Shi, Z. Wu, J. Xiao, D. Wang, Z. Huang, and Z. Fang, "A review on ultra high performance concrete: Part I. Raw materials and mixture design," Constr. Build. Mater., vol. 101, pp. 741-751, 2015, doi: https://doi.org/10.1016/j.conbuildmat.2015.10.088.

[2] E. Shaheen and N. G. Shrive, “Cyclic loading and fracture mechanics of Ductal® concrete,” Int. J. Fract., vol. 148, no. 3, pp. 251260, 2007. https://doi.org/10.1007/s10704-008-9199-1.

[3] K. L. Scrivener, A. K. Crumbie, and P. Laugesen, "The interfacial transition zone (ITZ) between cement paste and aggregate in concrete," Interface Sci., vol. 12, no. 4, pp. 411-421, 2004. https://doi.org/10.1023/B:INTS.0000042339.92990.4c.

[4] L. Xu, F. Deng, and Y. Chi, "Nano-mechanical behavior of the interfacial transition zone between steel-polypropylene fiber and cement paste," Constr. Build. Mater., vol. 145, pp. 619-638, 2017. http://dx.doi.org/10.1016/j.conbuildmat.2017.04.035.

[5] Z. Wu, C. Shi, and K. H. Khayat, "Multi-scale investigation of microstructure, fiber pullout behavior, and mechanical properties of ultra-high performance concrete with nano-CaCO3 particles," Cem. Concr. Compos., vol. 86, pp. 255-265, 2018. https://doi.org/10.1016/j.cemconcomp.2017.11.014.

[6] A. Elsharief, M. D. Cohen, and J. Olek, "Influence of aggregate size, water cement ratio and age on the microstructure of the interfacial transition zone," Cem. Concr. Res., vol. 33, no. 11, pp. 1837-1849, 2003, doi: https://doi.org/10.1016/S00088846(03)00205-9.

[7] S. Zhao and W. Sun, "Nano-mechanical behavior of a green ultra-high performance concrete," Constr. Build. Mater., vol. 63, pp. 150-160, 2014. http://dx.doi.org/10.1016/j.conbuildmat.2014.04.029.

[8] L. Sorelli, G. Constantinides, F.-J. Ulm, and F. Toutlemonde, "The nano-mechanical signature of ultra high performance concrete by statistical nanoindentation techniques,” Cem. Concr. Res., vol. 38, no. 12, pp. 1447-1456, 2008. https://doi.org/10.1016/j.cemconres.2008.09.002.

[9] Z. Wu, C. Shi, K. H. Khayat, and S. Wan, "Effects of different nanomaterials on hardening and performance of ultra-high strength concrete (UHSC)," Cem. Concr. Compos., vol. 70, pp. 24-34, 2016, doi: https://doi.org/10.1016/j.cemconcomp.2016.03.003.

[10] Associação Brasileira de Normas Técnicas. Cimento Portland-Resquisitos, NBR 16697, 2018.

[11] F. Pelisser, P. J. P. Gleize, and A. Mikowski, "Structure and micro-nanomechanical characterization of synthetic calcium-silicatehydrate with Poly(Vinyl Alcohol)," Cem. Concr. Compos., vol. 48, pp. 1-8, 2014. https://doi.org/10.1016/j.cemconcomp.2014.01.004.

[12] W. C. Oliver and G. M. Pharr, "An improved technique for determining hardness and elastic modulus using load and displacement sensing indentation experiments," J. Mater. Res., vol. 7, no. 6, pp. 1564-1583, 1992. https://doi.org/10.1557/JMR.1992.1564.

[13] F. Pelisser, P. Gleize, and A. Mikowski, "Effect of the Ca/Si molar ratio on the micro/nanomechanical properties of synthetic C-S-H measured by nanoindentation," J. Phys. Chem. C., vol. 116, pp. 17219-17227, 2012, https://doi.org/10.1021/jp302240c.

[14] D. K. Chanda et al. "Synthesis of calcium based nano powders for application in conservation and restoration of heritage mortar," $S N$ Applied Sciences, vol. 2, no. 3, pp. 340, 2020. https://doi.org/10.1007/s42452-020-2138-0.

[15] A. Leemann and P. Lura, "E-modulus of the alkali-silica-reaction product determined by micro-indentation," Constr. Build. Mater., vol. 44, pp. 221-227, 2013. https://doi.org/10.1016/j.conbuildmat.2013.03.018.

[16] G. Constantinides and F.-J. Ulm, “The nanogranular nature of C-S-H,” J Mech Phys Solids, vol. 55, no. 1, pp. 64-90, 2007. https://doi.org/10.1016/j.jmps.2006.06.003.

[17] M. Vandamme, F.-J. Ulm, and P. Fonollosa, "Nanogranular packing of C-S-H at substochiometric conditions," Cem. Concr. Res., vol. 40, no. 1, pp. 14-26, 2010. https://doi.org/10.1016/j.cemconres.2009.09.017.

[18] J. Wambach, A. Wokaun, and A. Hiltpold, "Oxidation of stainless steel under dry and aqueous conditions: oxidation behaviour and composition," Surf Interface Anal., vol. 34, no. 1, pp. 164-170, 2002. https://doi.org/10.1002/sia.1275.

Author contributions: VFC: Conceptualization, Investigation, Writing-Original draft preparation, Methodology. FP: Supervision, Conceptualization, Methodology, Data curation, Writing-Original draft preparation, Writing- Reviewing and Editing. PJPG: Visualization, Investigation. MDM: Conceptualization, Methodology, Data curation.

Editors: Rebecca Gravina, Guilherme Aris Parsekian. 